\title{
Hak dan Kewajiban Hukum Bagi Pasien BPJS
}

\author{
Mitha Larasati Vidya Ningtiyas \\ IIK STRADA INDONESIA \\ Mithalarasati1803@gmail.com
}

\begin{abstract}
Abstrak
Program Jaminan kesehatan Nasional oleh BPJS Kesehatan, sebagai upaya untuk memberikan perlindungan kesehatan kepada peserta yang kurang mampu untuk memperoleh layanan kesehatan di rumah sakit. Pelaksanaan program BPJS kesehatan implementasinya sudah dapat berjalan dengan baik, namun peserta BPJS kesehatan dalam hal ini masih memiliki banyak keluhan dalam pelayanan fasilitas rumah sakit khususnya pasien BPJS kesehatan rawat inap. Perlindungan terhadap pasien BPJS rawat inap di rumah sakit dari aspek regulasi sudah terlindungi hak-haknya baik sebagai konsumen jasa atau sebagai pasien rumah sakit maupun sebagai peserta BPJS kesehatan.

Banyaknya pasien BPJS kesehatan yang belum mengerti tentang hak dan kewajiban peserta BPJS kesehatan, membuat para petugas kesehatan di fasilitas kesehatan sering kali terlibat konflik dengan pasien maupun keluarga pasien. Kondisi ini diperburuk dengan banyaknya kesenjangan antara peraturan yang diterapkan BPJS kesehatan dengan harapan peserta mendapat pelayanan yang ingin mereka dapatkan. Masalah serupa sering dijumpai pada fasilitas kesehatan yang bekerja sama dengan BPJS kesehatan.

Upaya hukum yang telah dilakukan oleh BPJS kesehatan dalam rangka memenuhi hak dan kewajiban pasien yaitu dengan menempatkan beberapa petugas BPJS kesehatan di rumah sakit untuk menangani prosedur keluhan oleh peserta BPJS kesehatan, serta melakukan upaya mediasi terhadap pihak peserta BPJS kesehatan dengan pihak rumah sakit apabila diperlukan.

Kata kunci : perlindungan hukum, pasien BPJS kesehatan, pemahaman hak peserta BPJS
\end{abstract}

\section{Latar Belakang}

BPJS adalah badan hukum yang dibentuk untuk menyelenggarakan program jaminan sosial. BPJS sendiri dibagi menjadi 2 jenis, yaitu BPJS kesehatan dan BPJS ketenagakerjaan. BPJS kesehatan adalah badan hukum yang dibentuk untuk menyelenggarakan program jaminan kesehatan. Tugas utama BPJS kesehatan adalah menyelenggarakan jaminan kesehatan nasional (JKN) bagi warga negara Indonesia. Pelayanan kesehatan yang 
dijamin oleh BPJS mencakup pelayanan promotif, preventif, kuratif, dan rehabilitative termasuk pelayanan obat dan bahan medis habis pakai sesuai kebutuhan medis yang diperlukan. Namun dalam penerapan program BPJS kesehatan sering ditemukannya permasalahan-permasalahan yang terjadi diantaranya permasalahan antara pihak peserta BPJS kesehatan dengan pihak rumah sakit sehingga pasien BPJS kesehatan merasa tidak mendapatkan pelayanan sesuai dengan ketentuan yang berlaku dan cenderung merasa dirugikan oleh pihak rumah sakit sendiri.

Hak dan kewajiban peserta dalam menjamin terselenggranya jaminan kesehatan yang mencakup seluruh pendduduk Indonesia dijelaskan dalam peraturan BPJS No. 1 tahun 2004. Keikut sertaan masyarakat dalam BPJS kesehatan itu sangat penting untuk menjamin haknya memperoleh hidup sehat. Ketika membicarakan hak maka selalu berkaitan dengan erat dengan kewajiban, begitupun dalam hal ini, agar masyarakat dapat memperoleh haknya dalam kesehatan yang baik maka harus juga memperhatikan kewajibannya sebagai pengguna pelayanan kesehatan. Masyarakat sebagai pemakai yang memperoleh layanan harus paham akan layanan yang akan didapatkan dan paham juga proses untuk mendapatkan pelayanan yang optimal dengan mengikuti BPJS kesehatan yang kini sedang dicanangkan.

\section{Kasus/Masalah}

Sering kali terjadinya penolakan peserta pasien BPJS kesehtaan saat akan berobat ke rumah sakit. Terkadang rumah sakit menolak peserta pasien BPJS dengan dalih penuhnya kuota pelayanan BPJS kesehatan. Oleh karena itu perlu di tegakan hukum untuk melindungi hak dan kewajiban peserta BPJS kesehatan agar mendapat pelayanan serta fasilitas kesehatan yang memadahi tanpa di anak tirikan dengan pasien yang tidak menggunkan layanan BPJS kesehatan.

\section{Tinjauan Pustaka}

Kesehatan adalah Hak Asasi Manusia (HAM) berdasarkan Universal Declaration of Human Right pasal 25 ayat 1 menyatakan bahwa setiap orang berhak atas taraf hidup yang menjamin kesehatan dan kesejahteraan untuk dirinya dan keluarganya. Dalam Pasal 28 huruf (h) Undang-Undang Dasar Negara Republik Indonesia Tahun 1945 menyebutkan bahwa: “ Setiap orang berhak hidup sejahtera lahir dan batin, bertempat tinggal dan mendapatkan lingkungan hidup yang baik dan sehat serta berhak memperoleh pelayanan kesehatan".

Sebagai perwujudannya, maka pemerintah Indonesia membentuk Sistem Jaminan Sosial Nasional sebagaimana dalam perubahan UUD 1945 ditindaklanjuti dengan Undang-Undang Nomor 40 Tahun 2004 tentang Sistem Jaminan Sosial Nasional yang selanjutnya disebut Undang-Undang SJSN, sebagai bukti bahwa pemerintah dan pemangku kepentingan terkait memiliki komitmen yang besar untuk mewujudkan kesejahteraan sosial bagi seluruh rakyatnya. Lalu, pada tanggal 1 Januari 2014, pemerintah merubah PT. Askes menjadi Badan 
Penyelenggara Jaminan Sosial yang di tindak lanjuti menjadi sebuah Undang-Undang Nomor 24 Tahun 2014 tentang Badan Penyelenggara Jaminan Sosial.Badan

\section{Pembahasan}

a. Perlindungan Hukum Terhadap Pasien BPJS kesehatan yang Dilakukan Rawat Inap di Rumah Sakit

Pasien BPJS kesehatan dalam hubungannya dengan rumah sakit sebagai pasien adalah orang sakit yang membutuhkan bantuan dokter untuk menyembuhkan penyakit yang diderita oleh pasien. Pasien adalah subyek yang memiliki pengaruh besar atas hasil akhir layanan, bukan hanya sekedar objek. Sebagai pasien di rumah sakit hak-hak pasien harus dipenuhi, mengingat kepuasan pasien menjadi barometer mutu pelayanan di rumah sakit. Berdasarkan pasal 32 Undang-Undang Nomer 44 Tahun 2009 tentang rumah sakit, hak-hak pasien di rumah sakit harus terjamin. Oleh karena itu, harapan pasien sebagai penerima pelayanan kesehatan meliputi:

$>$ Komunikasi yang baik dan memahami kebutuhan pasien.

$>$ Pemberian pelayanan yang di janjikan dengan segera dan memuaskan.

$>$ Membantu dan memberikan pelayanan dengan tanggap tanpa membedakan SARA (suku, ras, dan antar golongan).

$>$ Jaminan keamanan, keselamatan, dan kenyamanan.

b. Hak dan Kewajiban Belum Dipenuhi Kepada Pasien Peserta BPJS Kesehatan yang Dilakukan Rawat Inap di Rumah Sakit

Salah faktor yang paling penting dan untuk melihat sejauh mana adanya perlindungan hukum disuatu rumah sakit adalah terpenuhinya hak-hak pasien yang salah satunya adalah hak untuk mendapatkan informasi. Hak atas informasi ini terperoses secara revolusi, sejalan dengan perkembangan dari hak asasi manusia. Inti dari hak atas informasi yaitu hak pasien untuk mendapatkan informasi dari dokter, tentang hal-hal yang berhubungan dengan kesehatannya.

Beberapa penelitian menyatakan bahwa pasien BPJS kesehatan yang melakukan rawat inap di rumah sakit mengaku tidak mendapatkan haknya saat melakukan rawat inap maupun pelayanan kesehatan di rumah sakit. Terlebih lagi pasien sudah melakukan kewajibanya sebagaimana yang telah ditentukan oleh pihak BPJS kesehatan maupun pihak rumah sakit, sehingga pasien merasa dirugikan dalam memperoleh pelayanan kesehatan. Jika dilihat kembali, terlambatnya penanganan ataupun kurang mendapatkan informasi seputar kesehatan atau kondisi pasien BPJS kesehatan sehingga tak jarang pasien BPJS kesehatan mengalami kerugian yang tidak seharusnya mereka dapatkan jika pihak rumah sakit dapat melaksanakan kewajibannya kepada pasien. 
Fredmen Ameln di dalam berbagai literature hukum kesehatan menyatakan beberapa hak pasien, sebagai berikut:

a. Hak atas informasi

b. Hak memberikan persetujuan

c. Hak memilih dokter

d. Hak memilih sarana fasilitas kesehatan

e. Hak atas rahasia kedokteran

f. Hak menolak pengobatan/perawatan

g. Hak menolak suatu tindakan medis tertentu

h. Hak menghentikan pengobatan/perawatan

i. Hak atas second opinion (pendapat kedua)

j. Hak melihat rekam medis

Adapun kewajiban pasien yang diatur dalam UU No. 29 tahun 2004 tentang praktik kedokteran adalah :

a. Memberikan informasi yang lengkap dan jujur tentang masalah kesehatannya kepada dokter

b. Mematuhi nasihat dan petunjuk dokter dan dokter gigi

c. Memberikan imbalan jasa atas pelayanan yang diterima

d. Mematuhi ketentuan yang berlaku di sarana pelayanan kesehatan

\section{Upaya Hukum yang Dilakukan BPJS Kesehatan Dalam Rangka Memenuhi Hak dan Kewajiban Pasien}

Hukum yang terjadi dalam pelayanan medis ialah berdasarkan perjanjian yang bertujuan untuk melakukan pelayanan dan pengobatan demi kesembuhan pasien. Upaya pelayanan kesehatan di rumah sakit bertolak dengan hubungan dasar dalam bentuk transaksi Terapeutik. Transaksi Terapeutik bersifat mengikat antara pihak rumah sakit dengan pasien sebagai penerima pelayanan dalam suatu transasi Terapeutik tersebut.

Perikatan antara pemberi pelayanan kesehatan dengan pasien dapat dibedakan menjadi 2 dalam bentuk perjanjian yaitu:

$>$ Perjanjian perawatan, dimana terdapat kesepakatan dimana antara rumah sakit dengan pasien bahwa pihak rumah sakit menyediakan kamar perawatan serta menyediakan tenaga medis untuk penyembuhan.

$>$ Perjanjian pelayanan medis dimana terdapat kesepakatan antara rumah sakit dan pasien bahwa tenaga medis pada rumah sakit akan berupaya semaksimal mungkin untuk menyembuhkan pasien melalui tindakan medis.

Upaya yang dilakukan oleh pihak BPJS kesehatan untuk menunjang pelayanan kesehatan peserta BPJS kesehatan apabila mengalami kendala baik dari pihak rumah sakit atau pihak BPJS 
kesehatan itu sendiri dengan menempatkan beberapa petugas BPJS kesehatan di rumah sakit yang menjadi mitra BPJS kesehatan.

Ada beberapa upaya hukum yang dapat dilakukan peserta BPJS kesehatan untuk menuntut kerugian yang telah dilakukan oleh pihak rumah sakit, seperti pengajuan gugatan melalui pengadilan (litigasi) atau mediasi (non litigasi) yang di atur dalam pasal 29 UndangUndang Nomer 36 tahun 2009 tentang kesehatan.

\section{Kesimpulan}

$>$ Perlindungan hukum terhadap pasien BPJS kesehatan untuk rawat inap di rumah sakit dari aspek regulasi sudah terlindungi hak-haknya baik sebagai konsumen jasa atau pasien rumah sakit sebagai peserta BPJS kesehatan. Namun dalam penerapannya masih terdapat kekurangan yang membuat ketidakpuasan pasien terhadap pelayanan di rumah sakit, seperti kurangnya informasi yang diberikan oelh pihak rumah sakit kepada pasien BPJS kesehatan. Informasi yang dimaksud yaitu jumlah kamar yang tersedia dan besaran tarif apabila terjadi perubahan atau kenaikan kamar perawatan, serta fasilitas kesehatan di rumah sakit.

> Uapaya hukum yang telah dilakukan oleh pihak BPJS kesehatan untuk memenuhi hak dan kewajiban pasien adalah dengan menempatkan beberapa petugas BPJS kesehatan di rumah sakit untuk menangani keluhan dari pasien BPJS kesehatan. Selain itu, pihak BPJS kesehatan juga memasang dashboard informasi mengenai jumlah kamar yang tersedia untuk memenuhi hak dan kewajiban pasien BPJS kesehatan.

\section{Daftar Pustaka}

Fakih, M., \& Kasmawati, K. (2018). PERLINDUNGAN HUKUM TERHADAP PESERTA BPJS KESEHATAN DALAM PELAYANAN KESEHATAN DI RUMAH SAKIT. Pactum Law Journal, 1(02), 164-169.

https://scholar.google.com/scholar?hl=id\&as_sdt=0\%2C5\&q=Fakih\%2C+ M.\%2C+\%26+Kasmawati\%2C+K.+\%282018\%29.+PERLINDUNGAN+ HUKUM+TERHADAP+PESERTA+BPJS+KESEHATAN+DALAM+PE LAYANAN+KESEHATAN+DI+RUMAH+SAKIT.+Pactum+Law+Journ al $\% 2 \mathrm{C}+1 \% 2802 \% 29 \% 2 \mathrm{C}+164-$

169.\&btnG=\#d=gs_cit\&u=\%2Fscholar $\% 3 \mathrm{Fq} \% 3$ Dinfo $\% 3 \mathrm{AmRrbeNj} 8 \mathrm{JHgJ}$ \%3Ascholar.google.com\%2F\%26output\%3Dcite\%26scirp\%3D0\%26hl\%3 Did

Pramana, J. A., Arso, S. P., \& Kusumastuti, W. (2018). Analisis Upaya Kepatuhan Hukum Dalam Memenuhi Hak Dan Kewajiban Pasien Bpjs Kesehatan Di Rsud Ungaran. Jurnal Kesehatan Masyarakat (e-Journal), 6(5), 95-103. 
https://scholar.google.com/scholar?hl=id\&as sdt=0\%2C5\&q=ANALISIS+UPAYA +KEPATUHAN+HUKUM+DALAM+MEMENUHI+HAK++DAN+KEWAJIBAN+PASI EN+BPJS+KESEHATAN+DI+RSUD+UNGARAN\&btnG=\#d=gs cit\&u=\%2Fschola r\%3Fq\%3Dinfo\%3AgVvugODTmAEJ\%3Ascholar.google.com\%2F\%26output\%3 Dcite\%26scirp\%3D0\%26hl\%3Did

Prasetiawan, M. J., Mulyadi, E., \& Aliftitah, S. (2019). Pemahaman Tentang Hak Dan Kewajiban Peserta BPJS Kesehatan Di Puskesmas Ganding Sumenep. Journal Of Health Science (Jurnal IImu Kesehatan), 4(2), 25-27.

https://scholar.google.com/scholar?hl=id\&as_sdt=0\%2C5\&q=Pemahaman +Tentang+Hak+Dan+Kewajiban+Peserta+BPJS+Kesehatan+Di+Puskesm as++Ganding+Sumenep\&btnG=\#d=gs cit\&u=\%2Fscholar\%3Fq\%3Dinfo \%3AejnZKSKD2n4J\%3Ascholar.google.com\%2F\%26output\%3Dcite\%26 scirp\%3D0\%26hl\%3Did

Faradila, D. (2021). TINJAUAN YURIDIS HAK PASIEN PESERTA BADAN PENYELENGGARA JAMINAN SOSIAL (BPJS) KESEHATAN YANG BERSISTEM RUJUKAN BERJENJANG (Doctoral dissertation, UNIVERSITAS HASANUDDIN). https://scholar.google.com/scholar?hl=id\&as_sdt=0\%2C5\&q=TINJAUAN +YURIDIS+HAK+PASIEN+PESERTA+BADAN+PENYELENGGARA ++JAMINAN+SOSIAL+\%28BPJS\%29+KESEHATAN+YANG+BERSIS TEM+RUJUKAN++BERJENJANG\&btnG=\#d=gs_cit\&u=\%2Fscholar\%3 Fq\%3Dinfo\%3AXW7U-

hwGr50J\%3Ascholar.google.com\%2F\%26output\%3Dcite\%26scirp\%3D0 \%26hl\%3Did 